\title{
First -trimester in comparison to second trimester detailed anomaly scan in diagnosis of fetal congenital anomalies in pregnant women with pregestational diabetes
}

\author{
Original \\ Article \\ Mahmoud Al Alfy', Hasan Kamel', Mohamed Ismail', Aboushady, Ahmed \\ Ellithy $^{3}$,Yousra Lasheen ${ }^{3}$ \\ ${ }^{1}$ Fetal Medicine Unit, Cairo University, Cairo, Egypt, ${ }^{2}$ Department of Obstetrics and \\ Gynecology, Alazhar University, Egypt, ${ }^{3}$ Department of Obstetrics and Gynecology, Cairo \\ University, Egypt
}

\begin{abstract}
Background: Pregestational Diabetes mellitus increases the risk of fetal congenital Structural abnormalities . Ultrasonographic evaluation of a fetus of pregnant mothers.

With pregestational D.M can be done early in first trimester (starting from 11 weeks +1 day) also in second trimester scan we can diagnose another abnormalities later in pregnancy.

Aim of the work : Assessment of the accuracy of first Trimester anomaly scan versus the second Trimester anomaly scan in Diabetic pregnant women. In diagnosis of fetal congenital anomalies.

Methods : 2D and 3 D Ultrasound was performed to 2500 pregnant women With pregestational D.M and to 300 pregnant women with no medical disorders both in first trimester(11weeks +1 day ) And then in second trimester (at 18 weeks till 24 weeks) -Tei index (myocardial performance index) was also done HbA1c was done .

Results : Our study indicates a higher percent of congenital anomalies in diabetic pregnant Mothers than non diabetic pregnant women.

Conclusion: From our study, we concluded that $1^{\text {st }}$ trimester scan offers an early noninvasive method of prenatal diagnosis of fetal congenital abnormalities. Especially $1^{\text {st }}$ trimester scan, we can diagnose major brain anomalies (Anencephaly, Acrania), anterior abdominal wall defects (Gastroschisis, omphalocele) neural tube defects ( encephaloce) some renal anomalies (renal agenesis) But other structural fetal congenital anomalies needs a detailed 2nd trimester scan.
\end{abstract}

Key Words: early scan, fetal anomalies, pregestational diabetes.

Received: 4 April 2017, Accepted: 2 May 2017

Corresponding Author: Ahmed Lithy, Department of Obstetrics and Gynecology, Cairo University, Egypt, Tel.: 01120205000, E-mail: mahmoudalalfy@ymail.com

ISSN: 2090-7265, August 2017, Vol. 7, No. 3

\section{INTRODUCTION}

Women with pregestational diabetes mellitus are at substantially increased risk for having a fetus with congenital anomalies.

This risk is related to periconceptional glycemic control as evidenced by the higher frequency of fetal anomalies in women with raised glycosylated hemoglobin ( $\mathrm{HbA} 1 \mathrm{c})$ levels at the beginning of pregnancy. (Miller, et al, 1981) (YlinenK, et al, 1984) (Lucas MJ, et al 1989).

Fetal anomalies predominantly involve cardiac, musculoskeletal, urogenitaland nervous systems and of these cardiovascular anomalies comprise the highest proportion and are the greatest contributer to perinatal mortality. (Sheffield JS et al, 2002) (Wender-o? egowska E, et al, 2005) and (Makrydimas G et al, 2003).

In recognition of the frequency and pattern of anomalies, typical prenatal screening for women withpregestational diabetes consists of a targeted second trimesrer ultrasound followed by fetal echocardiography.

However , since the risk for fetal anomalies in pregestational diabetes can already be estimated in early pregnancy by the HbAlc level these women may benefit from potential early detection of fetal anomalies in the first trimester. ( Jones KL, et al 1997) And (Souka AP, et al 2006).

Such early detection can offer the advantage of early consideration of management options, early risk stratification, and, if pregnancy termination is desired, the advantage of increased privacy and decreased cost, morbidity and mortality. ( Lawson H W et al, 1994).

First trimester ultrasound measurement of the fetal nuchal translucency (NT) thickness and integration of this measurement with additional parameters not only identifies risk for aneuploidy with greater accuracy than second trimester screening but also predicts fetal anomalies 
(Nicolaides KH. et al, 2011) And (Wald NJ et al, 2003) and (Sniiders RJ et al, 1998).

In addition to fetal aneuploidy, an increased NT and abnormal Ductus venosus flow velocity waveform can independently predict cardiovascular and renal anomalies and adverse perinatal outcome. (Oh C, Harman C, Baschat AA. 2007), (Haak MC 2003), (Maize N et al, 2008) And (Matias A et al 1998).

As many of the anomalies observed in pregestational diabetes are also associated with an increased NT and since the dimension of the NT appears to be independent of the $\mathrm{HbA} 1 \mathrm{c}$ or the degree of glycemic control. (Barth JL etal 2003), (Spencer K, 2005 ) and (Spencer K, et al , 2010 )

\section{Congenital Malformations Associated with Maternal Diabetes}

Congenital anomalies of the central nervous system (CNS), heart, and renal and urinary tracts, lower limb reduction defects, axial skeleton defects, and caudal dysgenesis complex are more frequent among the children of mothers with pregestational diabetes than among children with non-diabetic mothers (Martínez-Frías ML. et al, 1994).

For instance, the frequency of CNS anomalies is 2.9 times higher in children of pregestational diabetic mothers than in children of non-diabetic mothers (Martínez-Frías ML. et al, 1994).

Ray et al observed a higher risk of open neural tube defects and urinary tract disorders in association with the presence of pregestational diabetes among women undergoing second-trimester screening (Ray JG, 2004).

Gestational diabetes is associated with a significant risk of holoprosencephaly, upper/lower spine/rib defects, and renal and urinary system anomalies (Martínez-Frías ML et al, 1998).

\section{Caudal regression syndrome}

Caudal regression syndrome is characterized by varying degrees of vertebral anomalies from partial sacral agenesis to complete absence of the lumbosacral spine.It is the most characteristic congenital anomaly observed in the children of diabetic women (Martínez-Frías ML. et al, 1994).

\section{Neural tube defects}

Mills et al, found a twofold ratio of incidence of spina bifida, hydrocephalus, and other CNS defects and a threefold ratio of incidence of anencephaly in infants of diabetic mothers compared with those of controls. (Mills JL 1979).

\section{Congenital heart defects}

Congenital heart defects are the most frequent malformations but are not the most characteristic abnormalities among children of diabetic mothers with or without insulin treatment. Martínez-Frías found that congenital heart anomalies made up $21 \%$ of all anomalies among children of diabetic mothers; however, the frequency of congenital heart defects was only 2.8 times higher than that in children of non-diabetic mothers (Martínez-Frías ML. et al, 1994).

\section{Other anomalies}

Maternal diabetes is related to heterotaxia-asymmetry, particularly transposition of great vessels and transposition of viscera, but situs inversus totalis does not appear to be related to maternal diabetes (Martínez-Frías ML 2005).

The reported congenital malformations common to sonic hedgehog abnormalities and infants of diabetic mothers include aphallia, hypospadias, megalourethra, urogenital malformation sequence, hydronephrosis, renal agenesis, horseshoe kidneys, vertebral segmentation segmentation defects, polydactyly, sacral defects, limb deficiency, esophageal atresia, tracheoesophageal atresia, anal stenosis/imperforate anus, urorectal septum malformation sequence, intestinal malrotation/ atresia, holoprosencephaly, and cardiac laterality defects (Fuhrmann K 1983).

\section{PATIENTS AND METHODS}

This is a prospective, observational study of women with pregestational diabetes presenting for first-trimester screening at the cairo fetal medicine unit for Advanced Fetal Care from 2013 Till 2016.

The study protocol was approved by the ethical committee of Alzhar university.

Patients were signed an informed consent to share in the study.

\section{Inclusion criteria:}

\section{-Control:}

350 Pregnant women with no medical disorders coming for routine first trimester scan ( pregnant 11- 13 weeks +6 days )And then scanned in the 2 nd trimester.

--cases:

2000 pregnant women with pregestational diabetes mellitus coming for routine first trimester scan (pregnant 11- 13 weeks +6 days ) And then scanned in the $2^{\text {nd }}$ trimester. 
Were preexisting diabetes mellitus requiring medical therapy with confirmed viable intrauterine pregnancy in women who presented for first-trimester screening. diabetes history, and $\mathrm{HbAlc}$ were obtained as a part of routine clinical practice.

Diabetic pregnant Women either primigravida or multi gravid with no previous history of congenital anomalies in the previous pregnancies nor in their family .

\section{-Exclusion criteria :}

-Pregnant women first seen in second trimester D.M.

-Pregnant women with medical disorders other than

\section{-Twin pregnancy}

Patients agreed to follow-up evaluation as part of the study.

Women underwent a standardized first-trimester ultrasound examination between 110 and 136 weeks' gestation (crown-rump length [CRL], $45-84 \mathrm{~mm}$ ) and $2^{\text {nd }}$ Trimester detailed scan.

The gestational age was calculated from the last menstrual period based on the Naegele rule.

If there was one week discrepancy between the calculated gestational age and the CRL, the dates were adjusted to the latter.

\section{-Machines used in the study :}

1- GE Voluson 730

2- Medison X8

\section{Measurements performed in the first trimester}

CRL measurements can be carried out transabdominally or trans- vaginally.

A midline sagittal section of the whole embryo or fetus should be obtained, ideally with the embryo or fetus oriented horizontally on the screen.

\section{Measurement of NT}

NT measurements used for screening should only be done by trained and certified operators. NT can be measured by a transabdominal or transvaginal route.

Second Trimester detailed anomaly scan was done from 22 weeks.
-Tei Index (TI) (myocardial performance Index) and interventricular septum and ventricular free walls were done 2 times one in the 28 weeks and another time in late gestational age at 36 weeks to assess fetal myocardial performance both in diabetic and in non diabetic pregnant women and the effect of advance of GA of the fetus and The diabetes Mellitus effect on the (TI).

HbA1c was also done to the pregnant women in 24 weeks and in 36 weeks .

In addition to the CRL measurement, the examination included measurement of the NT; documentation of the head, brain, stomach, abdomen, bladder, and extremities .

The DV waveform was assessed by pulsed wave Doppler as previously described and the length of the examination was limited to 2 minutes with power settings adjusted to minimize fetal exposure.

Nasal bone was assessed and Tricuspid valve Doppler study was done for every patient.

An anomaly was defined as a malformation resulting from abnormal development. Major fetal anomalies were defined as malformations that are lethal, cause serious impairment, or require intervention.

NT thickness $9^{\text {th }}$ centile for CRL and reversal of the a-wave in the DV were evaluated as first-trimester predictors of fetal anomalies.

According to the recommendations of the American Diabetes Association, HbA1c _ 7\% defined poor glycemic control.

The presence of either an abnormal NT or DV was tested as a predictor of any fetal anomaly, major anomalies, and specific organ system anomalies.

\section{RESULTS}

From the above we concluded that $1^{\text {st }}$ Trimester scan offers an early non invasive method of prenatal diagnosis of fetal congenital abnormalities.

Especially ${ }^{1 s t}$ Trimester scan, we can diagnose major brain anomalies (Anencephaly, Acrania), anterior abdominal wall defects (Gastroschisis, omphalocele) neural tube defects (encephaloce ) some renal anomalies (renal agenesis).

- But other structural fetal congenital anomalies needs a detailed second Trimester scan.

-While prediction of chromosomal abnormalities (Trisomy 21 (down syndrome), Trisomy 18 (Edwards syndrome), Trisomy 13 (Patu syndrome) can be 
suspected in both first Trimester scan and also in the $2^{\text {nd }}$ Trimester scan.

But in the $1^{\text {st }}$ Trimester scan it is better as it is more accurate and recommended for early prenatal screening for chromosomal abnormalities by $1^{\text {st }}$ trimester scan including NT, Nasal bone ,Ductus venosus and Tricuspid valve Doppler study).

Also $1^{\text {st }}$ Trimester scan helps in prediction of congenital heart defects. To be accurately diagnosed in the $2^{\text {nd }}$ trimester.

So, when we have inceased NT and reversed DV , Tricuspid regurge and absent Nasal bone, we should offer double test and then Do Chorionic villous sampling (CVS) or Amniocentesis to diagnose fetal Trisomies.

-While in the second Trimester scan, there are ultrasonographic markers (called soft markers for chromosomal abnormalities) which are (Absent nasal bone, increased Nuchal fold thickness, choroid plexus cysts, Bilateral renal pyelectasis, echogenic foci in the heart and hyperechogenic bowel).

-When there is any of these finding in the $2^{\text {nd }}$ trimester scan, this suspect chromosomal abnormalities, So the next step will be amniocentesis to do fetal karyotyping to prove or exclude fetal chromosomal abnormalities.

Table 1: Percent of anomalies in the cases and control

\begin{tabular}{lcc}
\hline Anomalies & Cases & Controls \\
\hline Yes & 21 & 45 \\
Yes\% & $6.00 \%$ & $2.30 \%$ \\
No & 329 & 1955 \\
No\% & $94.00 \%$ & $97.75 \%$ \\
\hline
\end{tabular}

This table shows the percent of congenital anomalies that are present. In diabetic patients and in non diabetic control pregnant mothers Which indicates a higher percent of anomalies in diabetic pregnant Mothers.

Table 2: Percent of anomalies from total

\begin{tabular}{|c|c|c|c|}
\hline Anomalies & Cases & Controls & Total \\
\hline Yes & $21(6 \%)$ & $45(2.3 \%)$ & $66(2.8 \%)$ \\
\hline No & 329 & 1955 & 2284 \\
\hline Total & 350 & 2000 & 2350 \\
\hline$\chi^{2}$ & 15.346 & & \\
\hline $\mathrm{p}(\mathrm{df}=1)$ & 0.000 & & \\
\hline$\chi^{2}$ (Yates) & 14.003 & & \\
\hline $\mathrm{p}$ (Yates) & 0.000 & & \\
\hline
\end{tabular}

This table demonstrate the percentage of in all pregnant Women that were included in the study shows a percent of $2.8 \%$ have anomalies from total cases and control. 
Table 3: Percentage of every organ anomalies in the cases and control

\begin{tabular}{|c|c|c|c|c|}
\hline Anomalies & Cases & Cases\% & Controls & Controls $\%$ \\
\hline Cardiac & 8 & $38 \%$ & 6 & $13 \%$ \\
\hline Neural tube defects & 4 & $19 \%$ & 2 & $4 \%$ \\
\hline Cerebral & 3 & $14 \%$ & 8 & $18 \%$ \\
\hline Renal & 2 & $10 \%$ & 10 & $22 \%$ \\
\hline Face & 1 & $5 \%$ & 2 & $4 \%$ \\
\hline GIT & 1 & $5 \%$ & 5 & $11 \%$ \\
\hline Abd.wall & 1 & $5 \%$ & 4 & $9 \%$ \\
\hline Skeletal & 0 & $0 \%$ & 6 & $13 \%$ \\
\hline Increased NT & 1 & $5 \%$ & 2 & $4 \%$ \\
\hline Total & 21 & $100 \%$ & 45 & $100 \%$ \\
\hline
\end{tabular}

This table shows a percentage of anomalies of every specific organ .Both in cases and control and this indicates that the most common anomalies in cases are cardiac anomalies followed by vertebral. While in control group, the most common anomalies were renal anomalies then cerebral then cardiac anomalies respectively.

Table 4: Comparison between cases and control regarding Tei index, IVS thickness and free wall thickness and HGA1c

\begin{tabular}{|c|c|c|c|c|c|c|c|}
\hline \multirow[t]{2}{*}{ Item } & \multicolumn{3}{|c|}{ Group 1} & \multicolumn{3}{|c|}{ Group 2} & \multirow{2}{*}{$p$ value } \\
\hline & Mean & SD & $\mathrm{n}$ & Mean & SD & $\mathrm{n}$ & \\
\hline Tei index-28w & 0.575 & 0.025 & 350 & 0.439 & 0.036 & 2000 & 0.000 \\
\hline Tei index-36w & 0.646 & 0.026 & 350 & 0.472 & 0.035 & 2000 & 0.000 \\
\hline IVS thickness-28w & 5.501 & 0.133 & 350 & 4.753 & 0.25 & 2000 & 0.000 \\
\hline IVS thickness-36w & 6.267 & 0.203 & 350 & 5.159 & 0.196 & 2000 & 0.000 \\
\hline $\begin{array}{l}\text { Free vent.wall } \\
\text { thick- } 28 \mathrm{w}\end{array}$ & 5.559 & 0.178 & 350 & 4.443 & 0.246 & 2000 & 0.000 \\
\hline $\begin{array}{l}\text { Free vent.wall } \\
\text { thick-36w }\end{array}$ & 6.125 & 0.161 & 350 & 4.83 & 0.224 & 2000 & 0.000 \\
\hline $\mathrm{HbA} 1 \mathrm{c}-24 \mathrm{w}$ & 8.125 & 0.52 & 350 & 5.928 & 0.261 & 2000 & 0.000 \\
\hline HbA1c-36w & 9.26 & 0.36 & 350 & 6.424 & 0.43 & 2000 & 0.000 \\
\hline
\end{tabular}

This table shows that Tei index (myocardial performance index) is impaired (has higher values ) and increases with advance in gestational age in diabetic pregnant women than in non diabetic patients, also diabetic pregnant women have increased thickness of Free ventricular wall thickness and interventricular wall thickness That increases with gestational age more than in non diabetic mothers. Also level of $\mathrm{HbAlc}$ level is higher in diabetic patients and increases with GA more than non diabetic patients. 
Table 5: Comparison between anomalies diagnosed in $1^{\text {st }}$ Trimester compared to anomalies diagnosed in $2^{\text {nd }}$ Trimester in control group

\begin{tabular}{|c|c|c|c|c|c|c|c|}
\hline \multicolumn{8}{|c|}{ Control group } \\
\hline \multicolumn{2}{|l|}{$1^{\text {st }}$ trimester } & \multirow[b]{2}{*}{$\begin{array}{l}\% \text { of } \\
\text { total }\end{array}$} & \multirow[b]{2}{*}{$\begin{array}{l}\% \text { of } 1^{\text {st }} \\
\text { trimester }\end{array}$} & \multicolumn{4}{|c|}{$2^{\text {nd }}$ trimester } \\
\hline Anomaly & no. of cases & & & Anomaly & $\begin{array}{l}\text { no. of } \\
\text { cases }\end{array}$ & $\begin{array}{l}\% \text { of } \\
\text { total }\end{array}$ & $\begin{array}{l}\% \text { of } 2^{\text {nd }} \\
\text { trimester }\end{array}$ \\
\hline Acrania & 1 & $2 \%$ & $13 \%$ & VSD & 1 & $2 \%$ & $2 \%$ \\
\hline Omphalocele & 3 & $7 \%$ & $38 \%$ & AVSD & 1 & $2 \%$ & $2 \%$ \\
\hline Gastroschisis & 1 & $2 \%$ & $13 \%$ & Ebsteins anomaly & 1 & $2 \%$ & $2 \%$ \\
\hline Anencephaly & 1 & $2 \%$ & $13 \%$ & Fallots tetralogy & 2 & $4 \%$ & $4 \%$ \\
\hline \multirow[t]{22}{*}{ Increased Nuchal translucency } & 2 & $4 \%$ & $25 \%$ & Interrupted aortic arch & 1 & $2 \%$ & $2 \%$ \\
\hline & & & & Ventriculomegaly & 1 & $2 \%$ & $2 \%$ \\
\hline & & & & Holoprosencephaly & 1 & $2 \%$ & $2 \%$ \\
\hline & & & & Dandy walker & 2 & $4 \%$ & $4 \%$ \\
\hline & & & & Encephalocele & 1 & $2 \%$ & $2 \%$ \\
\hline & & & & Blackes pouch cyst & 2 & $4 \%$ & $4 \%$ \\
\hline & & & & Acrania & 1 & $2 \%$ & $2 \%$ \\
\hline & & & & Spina bifida & 2 & $4 \%$ & $4 \%$ \\
\hline & & & & Pyelectasis & 5 & $11 \%$ & $11 \%$ \\
\hline & & & & Posterior urethral valve & 2 & $4 \%$ & $4 \%$ \\
\hline & & & & Infantike polycystic kidney & 2 & $4 \%$ & $4 \%$ \\
\hline & & & & Multicystic dysplastic kidney & 1 & $2 \%$ & $2 \%$ \\
\hline & & & & Cleft lip & 2 & $4 \%$ & $4 \%$ \\
\hline & & & & Small intestinal obstruction & 3 & $7 \%$ & $7 \%$ \\
\hline & & & & Mesenteric cyst & 1 & $2 \%$ & $2 \%$ \\
\hline & & & & Esophageal atresia & 1 & $2 \%$ & $2 \%$ \\
\hline & & & & Omphalocele & 3 & $7 \%$ & $7 \%$ \\
\hline & & & & Gastroschisis & 1 & $2 \%$ & $2 \%$ \\
\hline & & & & Micromelia & 3 & $7 \%$ & $7 \%$ \\
\hline & & & & Achondoplasia & 2 & $4 \%$ & $4 \%$ \\
\hline & & & & Increased NT & 2 & $4 \%$ & $4 \%$ \\
\hline & & & & Talipes & 1 & $2 \%$ & $2 \%$ \\
\hline
\end{tabular}

This Table shows a Comparison between anomalies diagnosed in $1^{\text {st }}$ Trimester compared to anomalies diagnosed in $2^{\text {nd }}$ Trimester in control group 
Ahmed Lithy et al.

Table 6: Comparison between anomalies diagnosed in $1^{\text {st }}$ Trimester compared to anomalies diagnosed in $2^{\text {nd }}$ Trimester in cases group( Diabetics)

\section{DM group}

\begin{tabular}{|c|c|c|c|c|c|c|c|}
\hline \multicolumn{4}{|c|}{$1^{\text {st }}$ trimeter } & \multicolumn{4}{|c|}{$2^{\text {nd }}$ trimester } \\
\hline Anomaly & no. of cases & $\%$ of total & $\%$ of 1 st trimester & Anomaly & $\begin{array}{l}\text { no. of } \\
\text { cases }\end{array}$ & $\%$ of total & $\begin{array}{l}\% \text { of } 2 \mathrm{nd} \\
\text { trimester }\end{array}$ \\
\hline Renal agenesis & 1 & $5 \%$ & $25 \%$ & Omphalocele & 1 & $5 \%$ & $5 \%$ \\
\hline Encephalocele & 1 & $5 \%$ & $25 \%$ & $\begin{array}{c}\text { Large intestinal obstruction } \\
\text { Omphalocele }\end{array}$ & 1 & $5 \%$ & $5 \%$ \\
\hline Omphalocele & 1 & $5 \%$ & $25 \%$ & Spina bifida & 4 & $18 \%$ & $18 \%$ \\
\hline \multirow{13}{*}{$\begin{array}{l}\text { Increased } \\
\text { Nuchal } \\
\text { translucency }\end{array}$} & 1 & $5 \%$ & $25 \%$ & $\begin{array}{l}\text { Dandy walker malformation } \\
\text { and Triventriculonegaly }\end{array}$ & 1 & $5 \%$ & $5 \%$ \\
\hline & & & & Agenesis of corpus callosum & 1 & $5 \%$ & $5 \%$ \\
\hline & & & & Multicystic dysplastic kidneys & 1 & $5 \%$ & $5 \%$ \\
\hline & & & & Anencephaly & 1 & $5 \%$ & $5 \%$ \\
\hline & & & & Cleft lip and palate & 1 & $5 \%$ & $5 \%$ \\
\hline & & & & VSD & 3 & $14 \%$ & $14 \%$ \\
\hline & & & & DORV & 2 & $9 \%$ & $9 \%$ \\
\hline & & & & DOLV & 1 & $5 \%$ & $5 \%$ \\
\hline & & & & Fallots tetralogy & 1 & $5 \%$ & $5 \%$ \\
\hline & & & & TGA & 1 & $5 \%$ & $5 \%$ \\
\hline & & & & Renal agenesis & 1 & $5 \%$ & $5 \%$ \\
\hline & & & & Increased Nuchal translucency & 1 & $5 \%$ & $5 \%$ \\
\hline & & & & Encephalocele & 1 & $5 \%$ & $5 \%$ \\
\hline
\end{tabular}

This Table shows a comparison between anomalies diagnosed in $1^{\text {st }}$ Trimester compared to anomalies diagnosed in $2^{\text {nd }}$ Trimester in cases group (Diabetics ) 


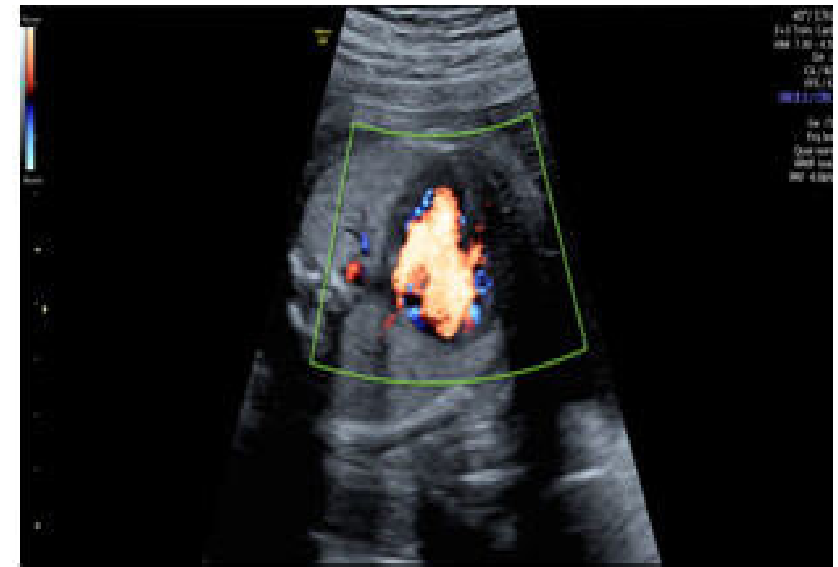

Fig. 1: AVSD (Atrioventricular septal defect).

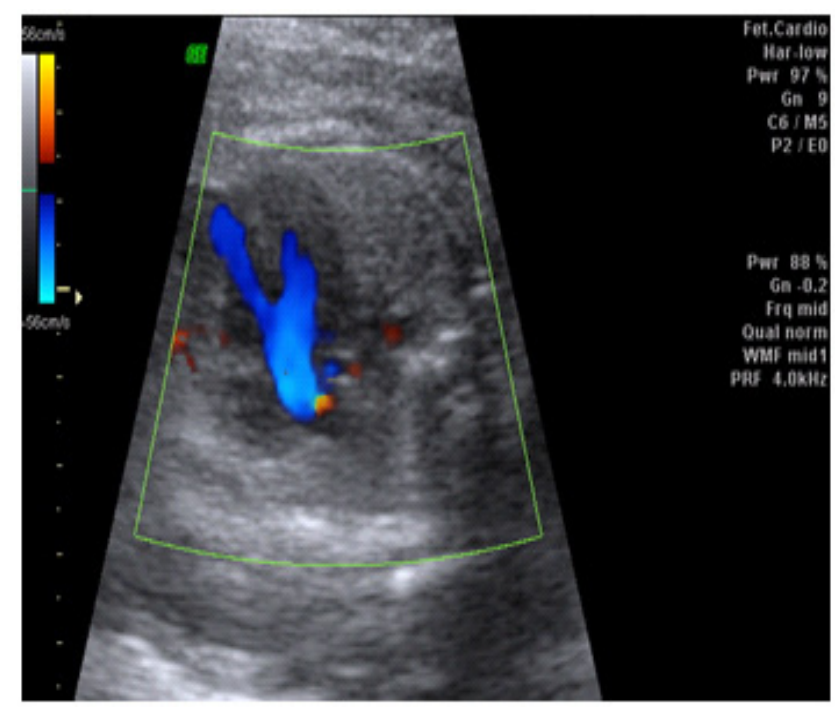

Fig. 2: Fallots tetralogy Showing overriding aorta

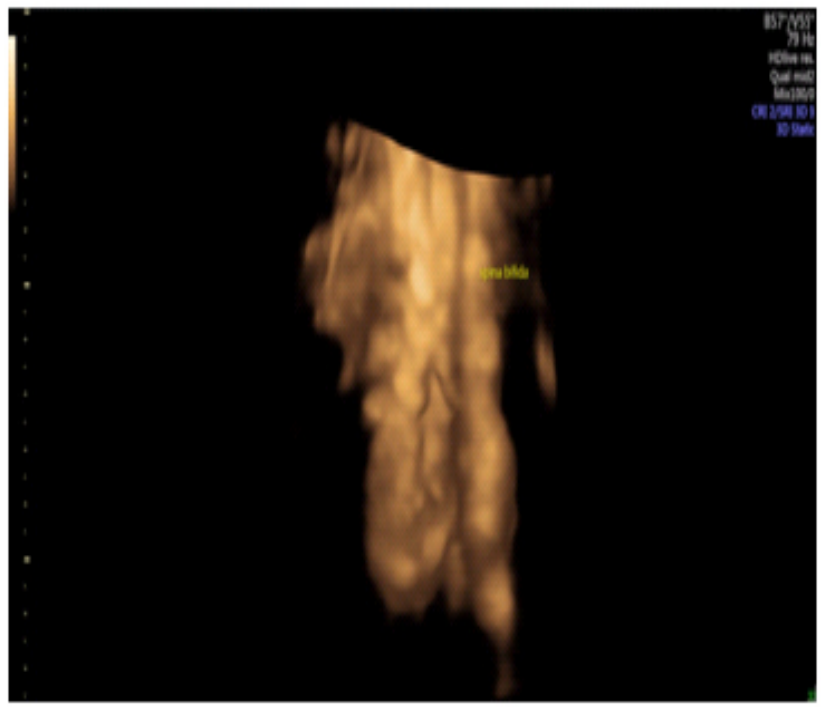

Fig. 3: F3 D rendering image showing spina bifida With sacraldefect.

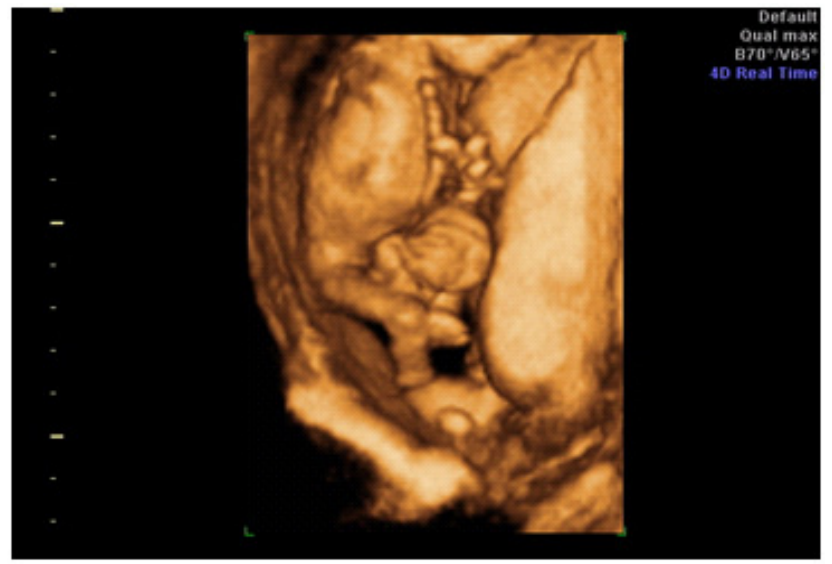

Fig. 4 : Gastroschisis by 3 D : A 3 D rendering image showing a large anterior abdominal wall defect Containing the intestinal loops.

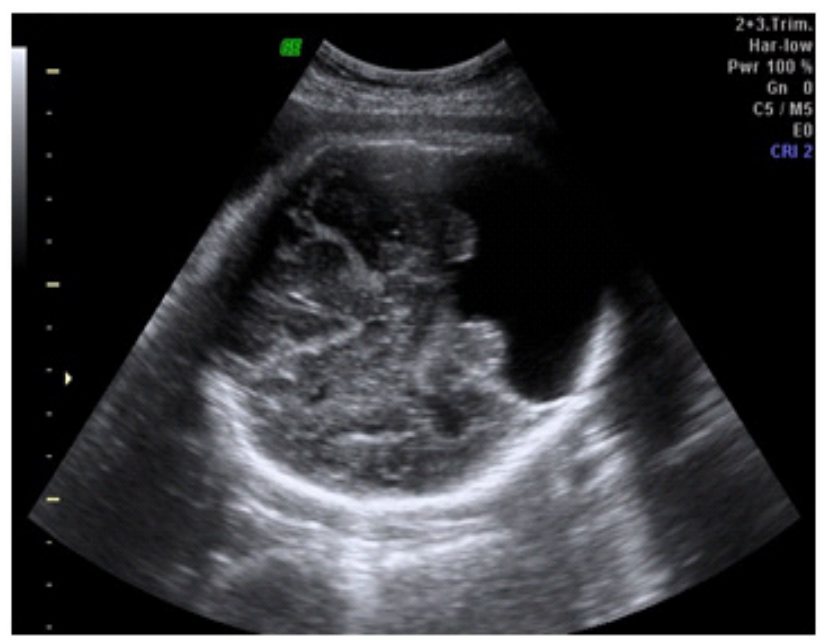

Fig. 5 : Gastroschisis by 3 D : A 3 D rendering image showing a large anterior abdominal wall defect Containing the intestinal loops.

\section{DISCUSSION}

Women with pregestational diabetes mellitus are at substantially increased risk for having a fetus with congenital anomalies.

This risk is related to periconceptional glycemic control as evidenced by the higher frequency of fetal anomalies in women with raised glycosylated hemoglobin (HbA1c) levels at the beginning of pregnancy. (Miller,et al 1981) (YlinenK, et al 1984) Lucas MJ,et al 1989).

Fetal anomalies predominantly involve cardiac, musculoskeletal, urogenitaland nervous systems and of these cardiovascular anomalies comprise the highest proportion and are the greatest contributer to perinatal mortality. (Sheffield JS et al, 2002), (Wendero? egowska E, , 2005) and (Makrydimas G et al, 2003) 
In recognition of the frequency and pattern of anomalies, typical prenatal screening for women with pregestational diabetes consists of a targeted second trimesrer ultrasound followed by fetal echocardiography.

In our study, we had a control group (2000 pregnant women) with no medical disorders from them we had 45 pregnant women to have fetal congenital anomalies that represent $(2.3 \%)$ from the control group.

While in the cases group (350 pregnant women that have pregestational Diabetes mellitus) we found 21 cases that had fetal congenital anom alies (that represent $6 \%$ of the cases group).

-This indicates that pregnant women with pregestational D.M are at higher risk to have a fetus with congenital anomalies that pregnant women with no medical disorders.

In our study we found that in pregnant women with pregestational D.M, 8 cases were diagnosed with congenital heart diseases that represent $38 \%$ of the congenital anomalies of the cases group and 4 cases with neural tube defects (spina bifida) that represent $19 \%$ of the anomalies in the cases. (Tables $1-3$ ), (Figs 1- 5) .

This indicates that congenital heart diseases are the most common anomalies in the fetuses of women with pregestational D.M followed by spina bifida as a second common anomalies. While in the control group, it was found that the most common the cerebral anomalies congenital anomalies are the renal anomalies $10(22 \%)$ followed by cerebral anomalies 8 cases $(18 \%)$ then followed by congenital heart diseases $(13 \%)$.

Jena L.et al, in 2013 in a previous study on first trimester diabetic pregnant mothers found Seventeen women had an anomalous fetus, of which 7 cases were major anomalies and 10 were minor anomalies. Major anomalies were diagnosed at each examination with most of them being identified in the first trimester ( $\mathrm{n}$ $2,28.6 \%$ ) or at the time of fetal echocardiogram ( $\mathrm{n} 3$, $42.9 \%$ ). The second-trimester detailed anatomy scan and interval growth scan each identified 1 fetus with a major anomaly.

In the cases group, we had 1 pregnant women in the $1^{\text {st }}$ Trimester scan that have increased Nuchal Translucency (NT measured $3 \mathrm{~mm}$ ) That was above normal range for GA

Then Double test was done and its result was normal then second trimester scan was done and revealed structurally normal fetus but with 2 soft markers of chromosomal abnormalities (Bilateral choroid plexus cysts and bilateral mild pyelectasis, so amniocentesis was offered to the patient and was done at 20 weeks and fetal karyotyping revealed $47 \mathrm{XX}$ female fetus (Trisomy 21).

While in the control group we had 2 fetuses with increased Nuchal Translucency in the $1^{\text {st }}$ Trimester scan, in the first fetus we had NT was $2.8 \mathrm{~mm}$, double test was normal, second Trimester scan revealed no fetal abnormalities so, amniocentesis wasnot offered and fetus was normal male.

The $2^{\text {nd }}$ fetus had increased NT 3,5 mm with absent nasal bone

Double test was positive so $2^{\text {nd }}$ Trimester scan was done early and revealed 4 soft markers increased Nuchal fold thickness measured $6.5 \mathrm{~mm}$, echogenic focus in the heart and hyperechogenic bowel and absent nasal bone so amniocentesis was done andfetla karyotyping rvealed $47 \mathrm{xy}$ (Down syndrome).

From our study we had 4 cases out of 21 cases from the women with pregestational D.M that was diagnosed in the first Trimester scan that were (Encephalocele, omphalocele, Renal agenesis in addition to the fetus that had increased NT).

Where as in the control group the cases that have abnormalities in the $1^{\text {st }}$ Trimester was 8 cases (on case Acrania, onecase anencephaly, on case of Gastroschisis and 3 cases of omphalocele in addition to 2 cases of increased NT).

This indicates that anomalies that can be diagnosed in the $1^{\text {st }}$ Trimester are (anomalies of the head, anterior abdominal wall defects, some of the renal abnormalities plus neural tube defects).

In the second Trimester scan, in the cases group we diagnosed 17 anomalies which were (cardiac, spinal defects, cerebral, face, renal Intestinal abnormalities).

Where as in the control group, we diagnosed 37 anomalies.

In the second Trimester which were (cardiac, cerebral, skeletal, spina bifida, renal, face and intestinal anomalies).

-From the above we concluded that $1^{\text {st }}$ Trimester scan offers an early noninvasive method of prenatal diagnosis of fetal congenital abnormalities .

Especially $1^{\text {st }}$ Trimester scan, we can diagnose major brain anomalies (Anencephaly, Acrania), anterior abdominal wall defects (Gastroschisis, 
omphalocele) neural tube defects (encephaloce) some renal anomalies (renal agenesis).

But other structural fetal congenital anomalies needs a detailed second Trimester scan.

While prediction of chromosomal abnormalities (Trisomy 21) (down syndrome), Trisomy 18 (Edwards syndrome), Trisomy 13 (Patu syndrome) can be suspected in both first Trimester scan and also in the $2^{\text {nd }}$ Trimester scan.

But in the $1^{\text {st }}$ Trimester scan it is better as it is more accurate and recommended for early prenatal screening for chromosomal abnormalities by by 1 st trimester scan including NT, Nasal bone ,Ductus venosus and Tricuspid valve Doppler study).

Also $1^{\text {st }}$ Trimester scan helps in prediction of congenital heart defects To be accurately diagnosed in the 2 nd trimester.

So, when we have inceased NT and reversed DV, Tricuspid regurge and absent Nasal bone, we should offer double test and then Do Chorionic villous sampling (CVS) or Amniocentesis to diagnose fetal Trisomies.

-While in the second Trimester scan, there are ultrasonographic markers (called soft markers for chromosomal abnormalities) which are (Absent nasal bone, increased Nuchal fold thickness, choroid plexus cysts, Bilateral renal pyelectasis, echogenic foci in the heart and hyperechogenic bowel).

-When there is any of these finding in the $2^{\text {nd }}$ trimester scan, this suspect chromosomal abnormalities.

So the next step will be amniocentesis to do fetal karyotyping to prove or exclude fetal chromosomal abnormalities.

Diabetic embryopathy can affect any developing organ system, including the central nervous system (anencephaly, spina bifida, microcephaly, and holoprosencephaly), skeletal system (caudal regression syndrome, sacral agenesis, and limb defects), renal system (renal agenesis, hydronephrosis, and ureteric abnormalities), cardiovascular system (transposition of the great vessels, ventricular septal defects, atrial septal defects,coarctation of the aorta, cardiomyopathy, and single umbilical artery), and gastrointestinal system (duodenal atresia, anorectal atresia, and small left colon syndrome) [(Carpenter MW. 1998) and (Chen CP. 2004).
Jena L.et al, in 2013 , for cardiac anomalies and adverse outcome in patients with normal and increased NT thickness. Given the high rate and spectrum of anomalies in our population we expected a higher prediction rate integrating $\mathrm{HbA} 1 \mathrm{c}$, NT measurement, and DV Doppler. Although, the prediction was statistically significant our results indicate that at most $70 \%$ of anomalies can be predicted in patients at highest risk with $\mathrm{HbA1c} \_8.3 \%$ using NT screening alone. In our population, the majority of cardiac defects involved the ventricular septum. The proposed basis for the relationship between cardiac defects and an increased NT or reversed DV a-wave lies in the hemodynamic disturbance leading to increased central venous pressures.

Cardiomyopathy with ventricular hypertrophy and outflow tract obstruction may occur in as many as 30\% of $\mathrm{IDMs}^{[7]}$. The cardiomyopathy may be associated with congestive failure with a weakly functioning myocardium or may be related to a hypertrophic myocardium with significant septal hypertrophy and outflow tract obstruction. When cardiomegaly or poor perfusion and hypotension are present, performing echocardiography to differentiate between these processes is important.

These infants are also at an increased risk of congenital heart defects, including (most commonly) ventricular septal defect (VSD) and transposition of the great arteries (TGA). (Elmekkawi SF, 2015).

-In the second trimester, there was a difference between the control group (pregnant women without medical disorders) and the cases (pregnant women with pregestational D.M) in the level of HbA 1c that denotes to the diabetic control also the 2 groups are different in the myocardial performance index ( Tei Index) also they differ in the thickness of interventricular septum thickness and in thickness of free ventricular wall thickness in the 2 groups and changes also with the advance of gestational age.

The mean value of $\mathrm{HbA} 1 \mathrm{c}$ in the 24 weeks GA in the cases group was 8.125 while at 36 weeks it was increased to be 9.26 this indicates a poor diabetic control with the advance of gestational age (as these values are above the normal range for $\mathrm{HbA} 1 \mathrm{c}$ ).

Where in the control group the mean value of $\mathrm{HbA1c}$ was 5.928 at 24 weeks gestational age and it increased to become 6.424. These value are within normal reference range so indicates A good diabetic control. 
-In the case group, The mean value of Tei index (Myocardial performance index) that reflects myocardial function was $0.575 \mathrm{~s}$ at 20 weeks then become $0.646 \mathrm{~s}$ at 28 weeks, these values either at 20 weeks and at 36 weeks are above normal reference range for GA, this indicates the effect of D.M and its deleteriuos effects on the fetal myocardial structure and function in D.M during pregnancy .

-While in the control group, the mean value of Tei index was 0.439 at 20 weeks then become 0.472 at 28 weeks which are within normal reference values.

-Moreover, the effect of uncontrolled D.M in pregnant women With pregestational D.M on the myocardium was evident on the thickness of Interventricular septum and free ventricular wall thickness. Interventricular septum thickness mean value increased with gestational age from $5.5 \mathrm{~mm}$ at 20 weeks to become $6.267 \mathrm{~mm}$ at 28 weeks (which are above normal range at 36 weeks)-Where as in the control group the mean value of IV septum thickness was $4.753 \mathrm{~mm}$ then increased with GA to be $5.159 \mathrm{~mm}$ At 36 weeks but still normal for GA.

-In the case group Free ventricular wall thickness in D.M was $5.559 \mathrm{~mm}$ at 20 weeks Then become 6.125 $\mathrm{mm}$ at 28 weeks This become above normal only at 36 weeks with advance of GA.

-While in the control group, the mean value of free ventricular wall thickness was $4.443 \mathrm{~mm}$ at 20 weeks the become $4.83 \mathrm{~mm}$ at 28 weeks of age.

To evaluate cardiac function, both systolic and diastolic, throughout gestation.

Recently, an easily measured Doppler-derived index of left (LV) or right ventricular (RV) myocardial performance combining systolic and diastolic time intervals was described in the literature. (Tulzer G, et al., 1994).

The Tei Index (TI) has been reported to be a useful, noninvasive, Doppler-derived myocardial performance indexthat serves as a combined index of global myocardial function. By incorporating only time intervals, theindex is less dependent on anatomy or precise imaging. Furthermore, the TI is independent of both heart rate and ventricular geometry $(28,29)$. (Tulzer G, et al 1994) and (Tsutsumi T, et al, 1999).

From our study, we concluded that 1 st trimester scan offers an early noninvasive method of prenatal diagnosis of fetal congenital abnormalities.

Especially $1^{\text {st }}$ trimester scan, we can diagnose major brain anomalies (Anencephaly, Acrania) , anterior abdominal wall defects ( Gastroschisis, omphalocele) neural tube defects (encephaloce) some renal anomalies (renal agenesis).

But other structural fetal congenital anomalies needs a detailed 2 nd trimester scan.

While prediction of chromosomal abnormalities Trisomy 21 (Down syndrome), Trisomy 18 (Edwards syndrome), Trisomy 13 (Patu syndrome) can be suspected in both first Trimester scan and also in the $2^{\text {nd }}$ Trimester scan.

But in the 1st trimester scan it is better as it is more accurate and recommended for early prenatal screening for chromosomal abnormalities by $1^{\text {st }}$ trimester scan including NT, Nasal bone, Ductus venosus and Tricuspid valve Doppler study).

Also $1^{\text {st }}$ trimester scan helps in prediction of congenital heart defects to be accurately diagnosed in the 2 nd trimester.

So, When we have increased NT and reversed DV, Tricuspid regurge and absent Nasal bone, we should offer double test and then Do Chorionic villous sampling (CVS) or Amniocentesis to diagnose fetal trisomies

While in the second Trimester scan, there are ultrasonographic markers (called soft markers for chromosomal abnormalities) which are absent nasal bone, increased Nuchal fold thickness, choroid plexus cysts, Bilateral renal pyelectasis, echogenic foci in the heart and hyperechogenic bowel.

When there is any of these finding in the $2^{\text {nd }}$ trimester scan, this suspect chromosomal abnormalities.

So, the next step will be amniocentesis to do fetal karyotyping to prove or exclude fetal chromosomal abnormalities.

\section{CONFLICT OF INTEREST}

There are no conflicts of interest.

\section{REFERENCES}

1. Miller E., Harejw,ClohertyJP,etal.Elevated maternal hemoglobinA1c in early pregnancy and major congenital anomalies in infants of diabetic mothers. NEngl Med 1981;304:1331- 4.

2. (YlinenK,Aula P ,Stenman UH,Kesaniemikuokkanen $\mathrm{T}$, Teramo K.Risk of minor and major fetal 
malformations in diabetics with hugh hemoglobin A1c values in early pregnancy.BMJ 1984;289:345- 6 .

3. Lucas MJ,Leveno KJ, Williams L, Raskin P,WhallyPJ. Early pregnancy glycosylated hemoglobin,severity of diabetes, and fetal malformations.Am J ObstetGynecol 1989;161:426- 31.

4. Sheffield JS,Butler-koster EL ,Casey BM,Mclntire DD,Leveno KJ.Maternal diabetes mellitus and infant malformations.ObstetGynecol 2002;100:925 -30.

5. Wender-o?egowska E, Wroblewska K,Zawiejska A,Pietryga M, Szczapa J, Biczysko R. threshold values of maternal glucose in early diabetic pregnancy-prediction of fetal malformations. ActaObstetGynecolscand 2005;84:17- 25.

6. Makrydimas G, Sotiridis A, Loannidis JPA .Screening performance of first trimester nuchal translucency for major cardiac defects : ameta analysis . Am J ObstetGynecol 2003;189:1330- 5.

7. Jones KL, Morphogenesis and dysmorphogenesis. In: smith DW ,ed.recognizeable patterns of human malformation.Philadelphia :WB Saunders; 1997:695 -705.

8. Souka AP, Pilalis A ,Kavalakis I, et al.Screening for major structural abnormalities at the 11 to 14 week ultrasound scan. AM J ObstetGynecol 2006;194:393- 6 .

9. Lawson H W, Frye A ,AtrashHK,Smith JC, Scholman HB, RamickM.Abortionmortality,United States, 1972 through 1987.Am J ObstetGynecol 1994; 171:1365- 72

10. NicolaidesKH.Turing the pyramid of prenatal care .Fetal Diagn Ther2011;29:183- 96

11. Wald NJ , Huttly WJ , HackshawAk. Antenatal screening for Down syndrome with the quadripletest. Lancet 2003;361:853-6

12. Sniiders RJ ,Noble P, Seibire N ,Nicolaides K ,for the fetal medicine foundation first trimester screening group.UK multicenter project on assessment of risk of trisomy 21 by maternal age and fetal nuchal translucency thickness at $10-14$ weeks of gestation. LANCET 1998;351:343- 6.

13. Oh C, Harman C ,Baschat AA. ABNORMAL FIRST TRIMESTER DUCTUS VENOSUS BLOOD FLOW:arisk factor for adverse outcome in fetuses with normal nuchal translucency.UtrasoundObstetGynecol 2007;30:192 -6.

14. Haak MC ,Twisk JW ,Bartelings MM ,Gittenberger -de Groot AC,VanVugt JM. Ductusvenosus flow velocities in relation to the cardiac defects in first trimester fetuses with enlarged nuchal translucency. Am J ObstetGynecol 2003; 188:727- 33.

15. Maize N ,Valencia C, Emmanuel EE ,Stanboulidou I, Nicolaides KH. Screening for adverse pregnancy outcome by ductusvenosus Doppler At 116+13- weeks of gestation.ObstetGynecol 2008;112:598- 605 .

16. Matias A,Gomes C,Flack N,Montenegro N,Nicolaides KH. Screening for chromosomal abnormalities at 11- 14 weeks :the role of ductusvenosus blood flow. UltrasoundObstetGynecol 1998;12;380- 4.

17. Barth JL, Wood J, Kyle PM ,Soothill PW, The effect of metabolic control on fetal nuchal translucency in women with insulin ependent diabetes : a preliminary study.Ultrasound ObstetGynecol 2003;21:451 -4.

18. Spencer K, Cicero S ,Atzei A, Otigbah C ,Nicolaides $\mathrm{KH}$.The influence of maternal insulin dependent diabetes on fetal nuchal translucency thickness and first trimester maternal serum biochemical markers of aneuploidy.prenatDiag 2005;25:927- 9 .

19. Spencer K, Cowans NJ, SPENCER ce ,Achillea N.A reevaluation of the influence of maternal insulin dependent diabetes on fetal nuchal translucency thickness and first trimester biochemical markers of aneuploidy.prenatDiag 2010;30:937 -40.

20. Martínez-Frías ML. Epidemiological analysis of outcomes of pregnancy in diabetic mothers: identification of the most characteristic and most frequent congenital anomalies. Am J Med Genet 1994;51:108-13.

21. Ray JG, Vermeulen MJ, Meier C, Wyatt PR. Risk of congenital anomalies detected during antenatal serum screening inwomen with pregestational diabetes. Q J Med 2004;97: 651-3.

22. Martínez-Frías ML, Bermejo E, Rodríguez-Pinilla E, Prieto L, Frías JL. Epidemiological analysis of outcomes of pregnancy in gestational diabetic mothers. Am J Med Genet 1998;78: 140-5.

23. Mills JL, Baker L, Goldman AS. Malformations in infants of diabetic mothers occur before the seventh gestational week: implications for treatment. Diabetes 1979;28:292-3. 
24. Martínez-Frías ML. Heterotaxia as an outcome of maternaldiabetes: an epidemiology study. Am J Med Genet 2001;99: 142-6. 43. Vaux KK, Jones MC, Benirschke K, Bird LM, Jones KL. Megalourethra: a report of three cases associated with maternal diabetes and a review of the literature - is sonic hedgehog the common pathway? Am J Med Genet 2005;132A: 314-7.

25. Fuhrmann $\mathrm{K}$, Reiher $\mathrm{H}$, Semmler $\mathrm{K}$, Fischer $\mathrm{F}$, Fischer M, Glockner E. Prevention of congenital malformations in infants of insulin-dependent diabetic mothers. Diabetes Care 1983;6: 219-23.

26. Carpenter MW. Preventing birth defects: the challenges of diabetic fetotherapy and neural tube defects. Med Health R I 1998;81:127-9.

27. Chen CP. Perinatal identification of caudal regressionsyndrome and alobar holoprosencephaly in pregnancies with poor maternal metabolic control. Genet Counsel 2004;15: 495-8.
28. Tulzer G, Khowsathit P, Gudmundsson S, Wood D, Tian Z, Schmitt K, Huhta J. Diastolic function of the fetal heart during second and third trimester: A prospective longitudinal Doppler echocardiographic study. Eur J Pediatr 1994; 153:151-154.

29. Tsutsumi T, Ishii M, Eto G, Hota M, Kato H. Serial evaluation for myocardial performance in fetuses and neonates using a new Doppler Index. Pediatr Int 1999; 41: 722-727.

30. Jena L.et al in 2013 MAY 2013 American Journal of Obstetrics \& Gynecology 385.e5.

31. Elmekkawi SF, Mansour GM, Elsafty MS, Hassanin AS, Laban M, Elsayed HM. Prediction of Fetal Hypertrophic Cardiomyopathy in Diabetic Pregnancies Compared with Postnatal Outcome. Clin Med Insights Womens Health. 2015. 8:39- 43. 